\title{
KNOWLEDGE MAINTENANCE IN KNOWLEDGE-BASED PRODUCT DEVELOPMENT SYSTEMS
}

\author{
David Guerra and Robert Young \\ Wolfson School of Mechanical and Manufacturing Engineering \\ Loughborough University, Loughborough, Leicestershire, LE11 3TU, England
}

\begin{abstract}
Knowledge-Based Product Development Systems (KBPDS) are important tools for obtaining a competitive advantage and leverage using what the company "knows". An important characteristic of a KBPDS is providing the right knowledge to the right people at the right time in the right format, therefore structuring and maintaining knowledge within the KBPDS is critical for the future. This paper focuses on research concerned with knowledge maintenance using a manufacturing information models infrastructure in an integrated product development system.

This paper argues that the understanding of different types of knowledge, its structure and transformation in the product realisation process are key issues for product knowledge maintenance, which is important for the long-term use of a KBPDS.
\end{abstract}

\section{INTRODUCTION}

An important aim in human history has been to retain, transfer and improve knowledge. A country is powerful if it has the ability to take advantage of all the available knowledge and have the capability to apply this knowledge to human requirements. In this case, manufacturing companies have different systems of using knowledge to design and manufacture products. Nowadays, globalisation of the manufacturing industry and the worldwide competitive economy is forcing industrial leaders in the manufacturing and service sector to fully utilise the knowledge available. Through time, technologies have improved the knowledge used to develop products and, as a consequence, this knowledge has expanded. Under these circumstances, to improve product development decisions and to obtain a competitive advantage, industry must use up-to-date knowledge. Using KBPDS with out-of-date knowledge in the development of products can affect the competitiveness of the manufacturing company; as a consequence, these systems could fall into disrepute and no longer be used. This is one reason why the product knowledge must be readily maintained within the KBPDS.

Through time, tacit, explicit and implicit knowledge has been present in the product realisation process however, the understanding about it and its role in the design and manufacture of a product needs to be explained. Most research seems to suggest that knowledge maintenance in design and manufacture will continue to have an important role in design and manufacture. Mills and Goossenaerts (2000) stated it is 
important to understand what knowledge is necessary to the product realisation process and to move towards thinking of and implementing a knowledge infrastructure and product knowledge management. Beckett (2000) suggests that intellectual assets are more important than tangible assets in effectively achieving the aims of an organisation in the $21 \mathrm{st}$ century. Under those circumstances, intellectual assets are developed using knowledge and learning processes emphasising knowledge value. Young et al. (2000) identified that although advances in the use of computer systems in product design and manufacture have been significant in recent years, the necessity to develop flexible systems that can be readily maintained with up-to-date information still exists.

The findings of studies examining the use of various forms of Knowledge Based Engineering Systems, for example Cordova and Gutierrez (2000) focus on structuring the key designs and manufacturing knowledge to support decisions. However, this key knowledge needs to be maintained. Rezayat (2000) studied methods for managing product knowledge held within KBPDS to make them more effective, emphasising that to reuse the knowledge it must be first maintained in a persistent manner and then disseminated and shared in a practical manner through the development cycle. Although much work has been done to date, more studies need to be conducted to ascertain knowledge maintenance in KBPDS.

The aim of this paper is to discuss the types of knowledge in knowledge based product development systems using machining and assembly examples, and in addition, to show research ideas about knowledge availability and its maintenance to support design and manufacture decisions.

\section{MANUFACTURING KNOWLEDGE MODELS IN A PRODUCT REALISATION PROCESS}

This paper is a continuation of a Manufacturing Information Model (MIM) research idea, where a Product Model (PM) and a Manufacturing Model (MM) are considered as information and knowledge repositories. A PM has an infrastructure that provides a source and repository for information concerning a product under development, in comparison a MM is a similar concept but represents the capability of the manufacturing facility and can therefore provide manufacturing related input to design decision-making. According to information models to support machiningrelated activities, a KBPDS was developed from various components with the ability to share knowledge and information between a PM and a MM (Zhao et al., 2000).

Figure 1 depicts an information and knowledge structure with the premise that computation systems in integrated design and manufacture can provide support to engineers by offering them quality information on which to base their decisions. The current research focuses on resolving the problem of knowledge maintenance in knowledge based product development systems; therefore there is a significant link between manufacturing knowledge models and the current research. The research scope is depicted in Figure 1 using a magnifier. The authors are considering machining and assembly manufacturing processes to explore knowledge maintenance ideas, because, according to the different types of knowledge definitions, these processes are generally understood when easy manufacturing 
examples are used; however the knowledge maintenance ideas obtained can be applied to other manufacturing processes.

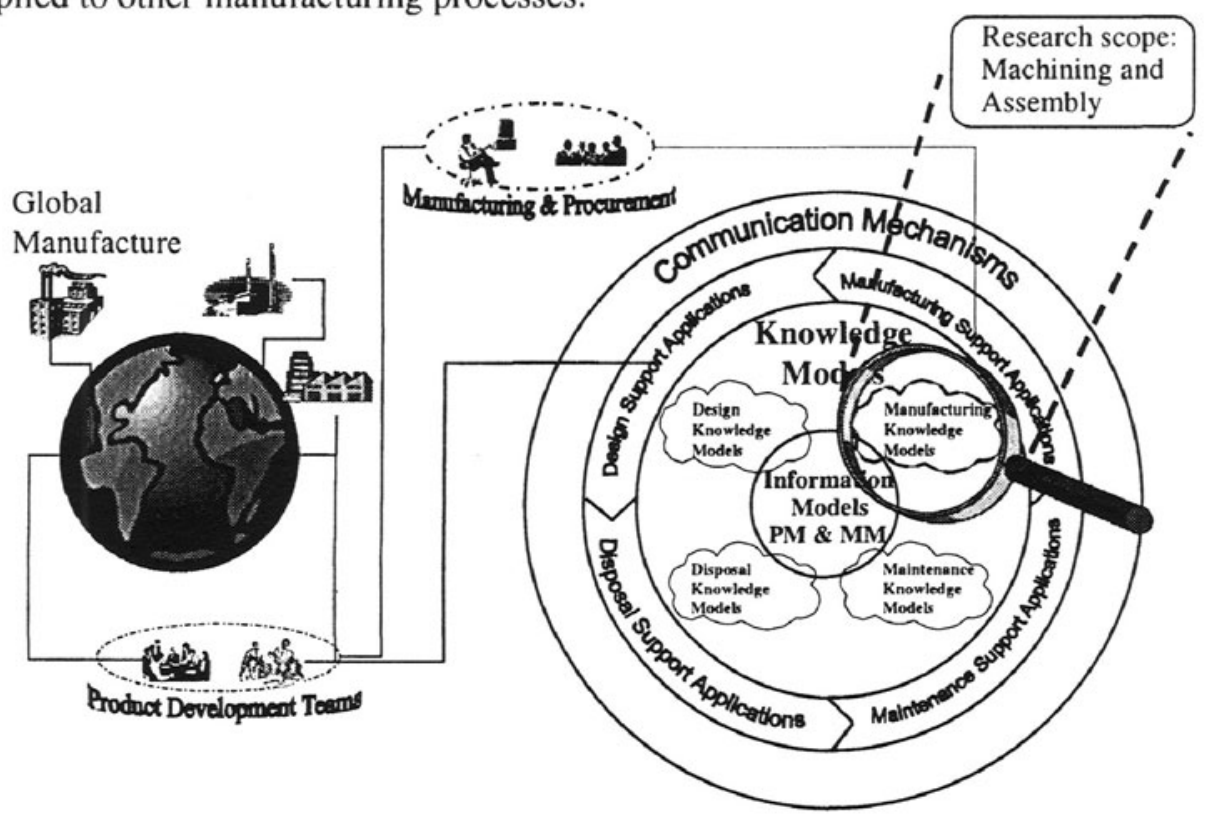

Figure 1 - Information and Knowledge Structure (Young et al., 2000).

KBPDS support decisions using key knowledge related to different activities in the product realisation process, the characteristic and content of the different knowledge depends on the type of users and the purpose of the KBPDS. The product realisation process includes different activities, but according to the aim of this paper only manufacturing activities and their relation with different types of knowledge are considered in order to develop knowledge maintenance ideas. Manufacturing activities apply different types of knowledge in order to produce a product. It is relatively easy to see a product, but conversely; it is not easy to see the complete piece of manufacturing knowledge needed to produce it. In order to suggest manufacturing knowledge structures in a KBPDS, it is firstly important to emphasise differences between data, information and knowledge. Secondly, it is necessary to move towards understanding the type of knowledge as well as the relation with the users and the use of the knowledge to produce a product.

Data can be symbols, words or numbers with no context and no interrelationship. Information is data structured with a particular meaning. Knowledge is information with added detail relating to how it may be used or applied to make decisions (Mills and Goossenaerts, 2000).

Several researchers have studied the different types of knowledge that humans use to make decisions. Nonaka (1995) suggested that tacit knowledge consists of personal relationships, practical experience and shared values; and explicit knowledge consists of formal policies and procedures. In addition, Zheng et al. (2000) observed that in contrast to the above two extreme components; implicit knowledge has a bridge property that links together the explicit and tacit components. Mascitelli (2000) noted that tacit knowledge is the context of innovation and observed that breakthrough innovations result from the harnessing of tacit knowledge possessed by individual and project teams. On the other hand, Ackerman and Halverson (1998) 
reported that there are other types of knowledge that can be managed out of the knowledge systems. However, in this paper only the different types of knowledge that can be structured and managed within KBPDS are analysed.

KBPDS use data, information and knowledge to support design and manufacturing decisions but in this paper mainly explicit, tacit and implicit machining knowledge are analysed.

\section{AN APPROACH TO MANUFACTURING KNOWLEDGE MAINTENANCE}

In this section a solution for the problem of knowledge maintenance in knowledge based product development systems is proposed. The identification of new knowledge and its transformation can be facilitated using suitable knowledge structures and applying a knowledge maintenance life cycle concept, as a consequence, the maintenance of current as well as new knowledge can be accomplished. In addition, knowledge expansion to other manufacturing processes can be achieved using this approach. The research work representation is depicted in figures 2.3 and 4 .

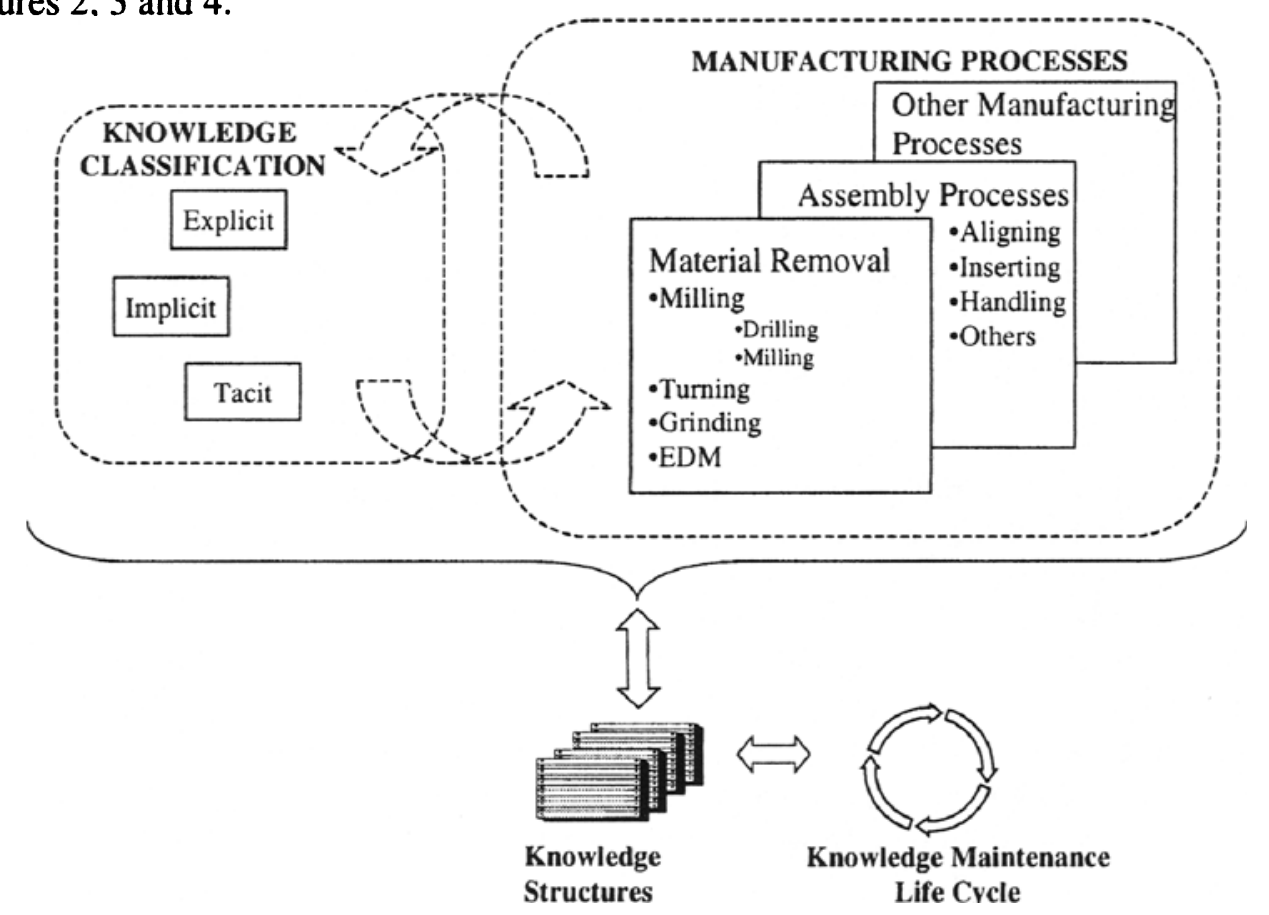

Figure 2 - Knowledge Structures and Knowledge Maintenance Life Cycle Representation.

Manufacturing knowledge related to machining processes is identified using explicit, tacit and implicit knowledge definitions. In order to manage the machining knowledge, the knowledge structures are used to up-date the different types of knowledge applying a knowledge maintenance life cycle concept. The knowledge structures suggested are explained in section 3.1 using different types of knowledge, manufacturing processes and different machining based features. In order to identify 
new knowledge related to the different machining processes as well as to expand to other manufacturing processes such as assembly it is necessary to have proper knowledge structures and apply a knowledge maintenance life cycle. The knowledge maintenance life cycle concept is discussed in section 3.2.

\subsection{Manufacturing Knowledge Structures}

Figure 3 shows the knowledge structures using different types of knowledge and manufacturing processes according to the scope of this research. The different types of machining knowledge are classified as explicit, tacit and implicit. In addition, these types of knowledge are sub-classified in different knowledge representations to make the knowledge maintenance possible.

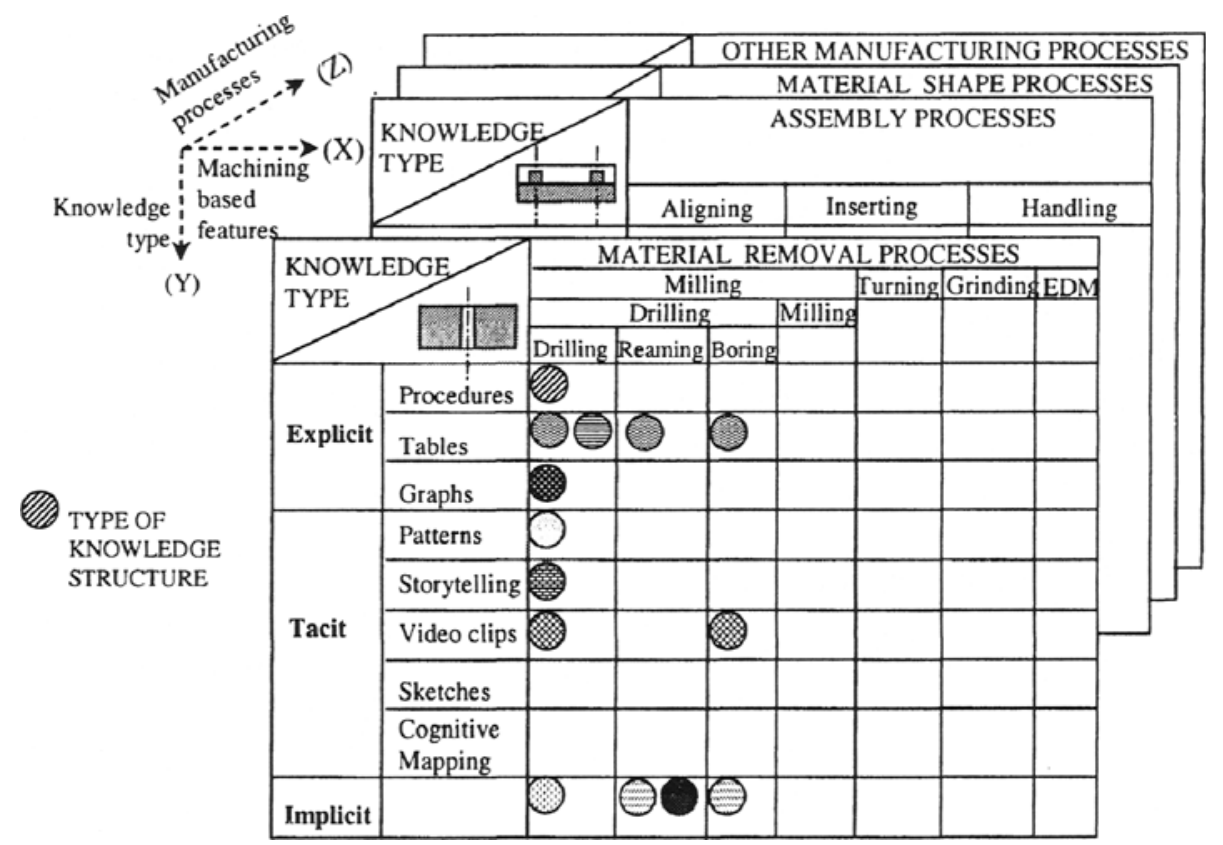

Figure 3 - Knowledge Structures and Manufacturing Processes Relationships.

Explicit knowledge is sub-classified into procedures, tables and graphs. These techniques of explicit knowledge representation are widely understood.

In the machining environment, tacit knowledge is practical experience that an expert operator develops through time whilst obtaining expertise to do machining operations. This type of knowledge is when an expert operator might use the common phrase "I know how to do this but I can't explain it". For these operators it is not easy to explain their tacit knowledge. It is necessary to use knowledge representation techniques to represent tacit knowledge and show new knowledge availability. Figure 3 also illustrates that tacit knowledge is structured in patterns, storytelling, video clips, sketches and cognitive mapping. Patterns are usually described using a format that includes a description of a problem and its solution, with additional information to support the solution of new problems. Storytelling describes a useful event in the past that can be utilised as reusable solutions to 
recurring problems which occurs during machining operations. Basically, storytelling can be structured as first, a strategic planner "set the stage", then "introduce the conflict", and finally a description of how the resolution to the problem was accomplished. Patterns and storytelling examples can be found in Malhotra (2000). The authors consider video clips and sketches as widely understood techniques of tacit knowledge representation. As an example of additional tacit knowledge representations, cognitive mapping will be the subject of further research.

Explicit, tacit and implicit knowledge representations can be linked together to expand the knowledge context and obtain greater knowledge availability.

The authors' hypothesis is that "Classifying the different types of manufacturing knowledge according to suitable structures helps the knowledge maintenance". At present it is possible to manage the different types of knowledge in a specific context and structure as shown in Figure 3 . The marked areas in figure 3 depict the different types of machining knowledge that has been currently structured.

Three dimensions are considered in order to populate the knowledge structures.

The (x) dimension is used as a reference to develop the knowledge structure according to machining based features (ISO/IS 10303-224.2, 2000).

The (y) dimension depicts explicit, tacit and implicit knowledge and its different knowledge representation. If a new type of knowledge or sub classification is identified can be added following the same format.

The $(\mathrm{z})$ dimension details the differem manufacturing processes. Drilling, reaming, boring, milling, grinding and turning are considered as machining processes and aligning, inserting and handling as assembly processes.

\subsection{Knowledge Maintenance Life Cycle}

Figure 4 depicts the knowledge maintenance life cycle concept, it identifies the main steps in order to up-date the different types of knowledge contained in the knowledge structures discussed in section 3.1.

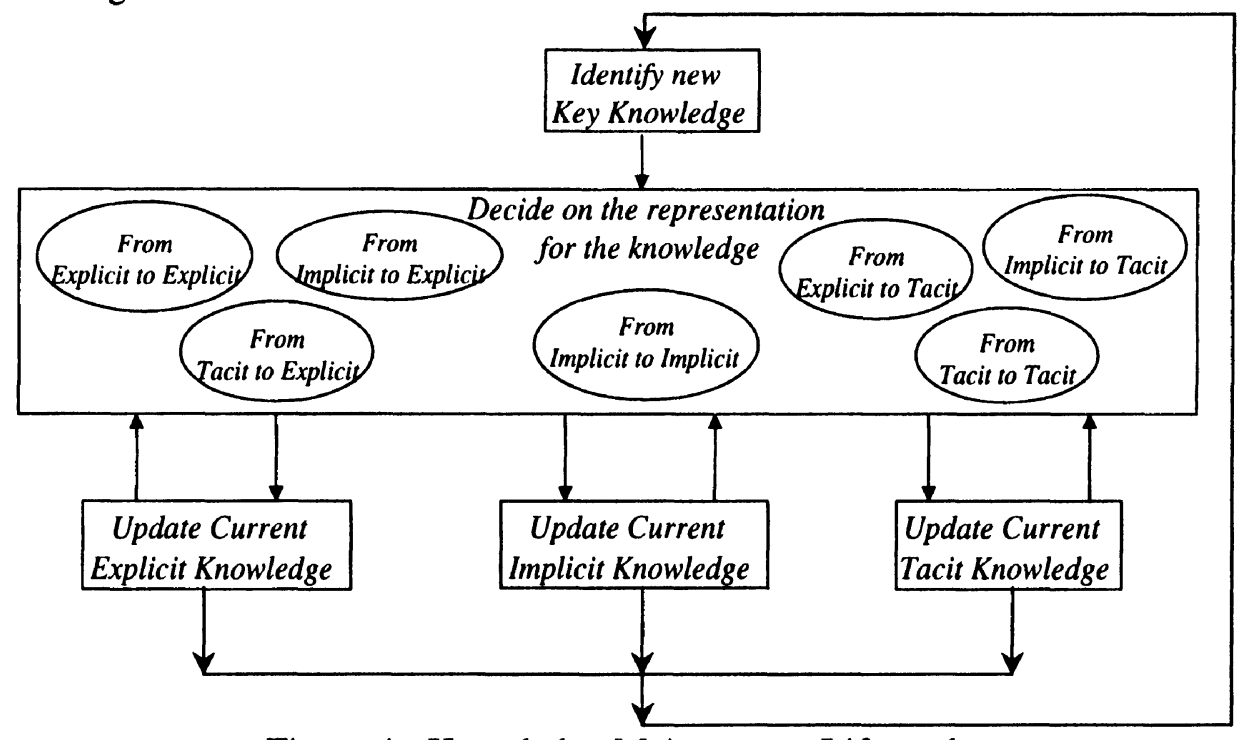

Figure 4 - Knowledge Maintenance Life cycle. 
Knowledge maintenance starts when new knowledge is identified. The next step is to decide on the representation for this new knowledge. This piece of new knowledge could be expressed in different explicit, tacit and implicit knowledge representations. The premise of this transformation is that the resulting knowledge should have "richer context" and provide better knowledge availability to those which use it to make decisions. The actions to up-date the explicit, tacit and implicit knowledge is the way in which new knowledge is identified and added or substituted into the knowledge structure discussed in section 3.1. Sometimes, updating current explicit, tacit or implicit knowledge could be a change of data or a piece of information related to any knowledge representation, but in other cases it could be necessary to generate a new procedure, table, graph, pattern, storytelling, sketch or cognitive mapping in order to represent the new knowledge. Using theses knowledge structures, it is possible to store and manage the creation of new knowledge.

\section{MANUFACTURING MODEL STRUCTURE}

A general representation to capture a manufacturing capability of a global facility in terms of resources, processes and strategies has already been defined and reported (Molina and Bell, 2002). However the current research extends Molina's approach with a significant relationship between strategies and knowledge structures in order to update the manufacturing knowledge by applying a knowledge maintenance life cycle concept. Figure 5 shows a UML class diagram of a manufacturing data model containing a manufacturing facility in terms of its resources, processes, strategies and types of knowledge.

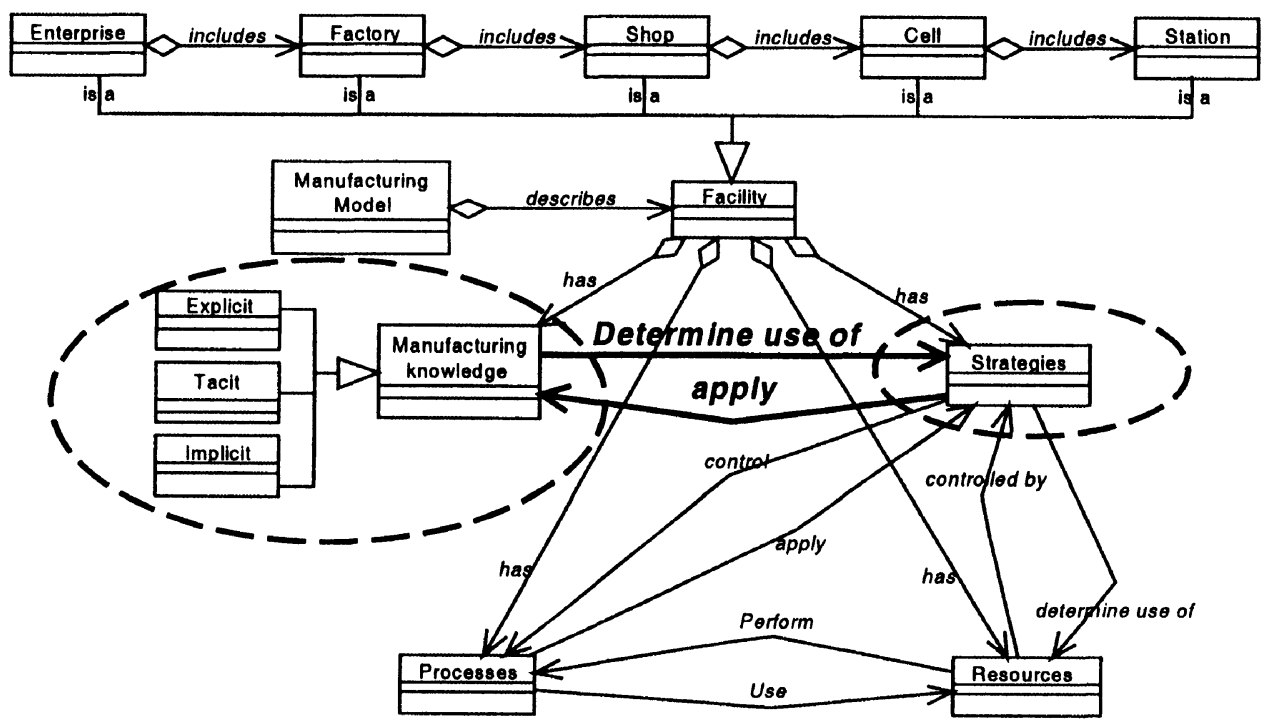

Figure 5 - A Manufacturing Data Model Representation.

\section{CONCLUSIONS AND FURTHER WORK}

A new approach for updating the manufacturing knowledge used in a knowledgebased product development system has been presented. The rationale behind this 
approach is to provide better understanding about manufacturing knowledge management. The value added up to now in this research is that even though some examples have been obtained between knowledge structures to support knowledge maintenance, additional research is needed to identify how and when manufacturing knowledge transformations happen and why a best knowledge representation take place. Future work will explore these additional research needs using machining and assembly knowledge. A manufacturing model is being constructed using UML, ObjectStore and Java to validate knowledge maintenance ideas.

\section{ACKNOWLEDGEMENTS}

The author acknowledges the support received by Loughborough University, and the supplementary support provided by CONACYT, MEXICO.

\section{REFERENCES}

1. Ackerman M. S., Halverson C., 1998, "Considering and Organisation's Memory”, in: Int. Conf. on CSCW'98, pp. 39-48, ACM Press, Seattle, WA.

2. Beckett R.C., 2000, Accessing Corporate Memory - Some Knowledge structure concepts. The 4th International Conference on Design of Information Infrastructure Systems for Manufacturing 2000. 15- 17 November, Melbourne, Australia.

3. Cordova J.L., Gutierrez A.M., 2000, Knowledge Based Engineering for Design and Manufacture of Glass Bottles, Integrated Manufacturing System Centre, Tools and methods of competitive engineering 3rd International symposium on tools and methods of competitive engineering. Horvath, I., Medland A., Vergeest J.S.M. (Editors); Delft University Press (Publisher); pp 263-274

4. ISO/IS 10303-224.2, 2000-12-01, International Organization for Standardization, Industrial Automation Systems and Integration, Product Data Representation Exchange Part 224.2, Application Protocol: Mechanical Product Definition for Process Planning using Machining Features.

5. Malhotra Y., 2000, "Knowledge Management and Virtual Organisations", Idea Group Publishing, ISBN 1-878289-73-X.

6. Mascitelli R., 2000, From Experience: Harnessing Tacit Knowledge to Achieve Breakthrough Innovation, J PROD INNOV MANAG 2000; 17: 179-193.

7. Mills J.J., Goossenaerts J., 2000, Toward information and knowledge in product realisation, The 4th International Conference on Design of Information Infrastructure Systems for Manufacturing, Melbourne, Australia. http://www.msa.cmst.csiro.au/DIISM2000

8. Molina A., Bell R., 2002, Reference Models for the Computer Aided Support of Simultaneous Engineering, International Journal of Computer Integrated Manufacturing,Vol. 15, No.3, pp 193-213.

9. Nonaka I., Takeuchi H., 1995, "The Knowledge-Creating Company," Oxford University Press, New York, Oxford.

10. Rezayat M., 2000, Knowledge-based product development using XML and KCs, Computer Aided Desing, www.elsevir.com/locate/cad

11. Young R.I.M., Dorador J.M., Zhao J., Cheung W.M., 2000, A Manufacturing Information Infrastructure to Link Team Based Design to Global Manufacture, The 4th International Conference on Design of Information Infrastructure Systems for Manufacturing, 15 - 17 November, Melbourne, Australia. http://www.msa.cmst.csiro.au/DIISM2000

12. Zhao J., Cheung W. M., Young R. I. M., 2000, The influence of manufacturing information models on product development systems, Engineering Design Conference, Brunel University, UK, 27-29th, June.

13. Zheng J., Zhou M., Mo J., 2000, Tharumarajah A., Background And Foreground Knowledge In Knowledge Management, The 4th International Conference on Design of Information Infrastructure Systems for Manufacturing, Melbourne, Australia, http://www.msa.cmst.csiro.au/DIISM2000 